\title{
PRÁTICAS DE EDUCAÇÃO FÍSICA COMO FERRAMENTA DE INCLUSÃO
}

\author{
José Carlos Arantes ${ }^{1}$
}

RESUMO: A presente pesquisa tem como objetivo averiguar de que maneira o trabalho do professor de Educação Física tem contribuído para o desenvolvimento inclusivo dos alunos que apresentam necessidades educacionais especiais. Realizou-se uma pesquisa bibliográfica em torno do termo inclusão e Educação Física. Para embasar a pesquisa bibliográfica, descritiva e qualitativa buscou-se teóricos como Rodrigues (2006), Alarcão (2003), Fonseca (2005), dentre outros. Após exaustivas leituras, reflexões acerca do tema, em que pese o crescente reconhecimento da educação inclusiva nas aulas de Educação Física, como forma prioritária para atender os alunos com necessidades educativas especiais, na prática, percebe-se um avanço alicerçado nos esforços em particular de cada educador, que procura no seu espaço de trabalho fazer o processo de inclusão, seja por atividades adaptadas, pelas técnicas e metodologias inseridas no contexto. Contudo, enfrentam obstáculos e dificuldades que se referem à falta de recursos materiais, causando com isso, um grande desconforto entre os professores. A inclusão deve ser compreendida a partir do entendimento de que todos devem abraçar a causa, as escolas devem ser reestruturadas para que os professores tenham condições de se capacitarem para atender a todos os alunos de modo igualitário.

Palavras - chave: Inclusão. Educação Física. Formação.

ABSTRACT: The present research aims to find out how the work of the Physical Education teacher has contributed to the inclusive development of students who have special educational needs. A bibliographical research was done around the term Inclusion and Physical Education. To support bibliographical, descriptive and qualitative research, we sought theorists such as Rodrigues (2006), Alarcão (2003), Fonseca (2005), among others. After exhaustive readings, reflections on the theme, in spite of the growing recognition of inclusive education in Physical Education classes, as a priority way to attend students with special educational needs, in practice, there is a progress grounded in the efforts of each educator, who seeks in his / her work space to make the inclusion process, either by adapted activities, by the techniques and methodologies inserted in the context. However, they face obstacles and difficulties that refer to the lack of material resources, causing with this, a great discomfort among teachers. Inclusion must be understood from the understanding

${ }^{1}$ Licenciatura Educação Física, Especialização: Motricidade, Treinamento e Performance Desportiva. Atualmente é professor do instituto Madre Marta Cerutti. E-mail: carlos.arantes_roma@hotmail.com. 
that everyone must embrace the cause, schools must be restructured so that teachers are able to be empowered to serve all students equally.

Keywords: Inclusion. Physical Education. Formation.

\section{INTRODUÇÃO}

Este artigo trata de discorrer acerca do acesso dos alunos em situação de deficiência em relação à inclusão educacional, principalmente no tocante a disciplina de Educação Física no que diz respeito à preparação para atender os alunos com necessidades educativas especiais. $\mathrm{Na}$ sociedade atual, o termo inclusão tem nas últimas décadas sido trabalho no sistema educacional. Esse fato mostra por meio da literatura científica nacional e internacional relacionada, que existe uma mudança que reflete como positiva nos últimos anos, por estar continuamente sendo discutida entre os professores nas questões de ambientes de aprendizagem inclusivos.

A Educação Física é projetada em eixos curriculares que respondem à didática, por sua vez estão diretamente relacionados a eventos econômicos, políticos, sociais e históricos, no meio acadêmico em que o ser humano se desenvolve, obtendo como resultado um currículo enquadrado dentro de objetivos psicológicos, cognitivos, biológicos e em busca do desenvolvimento e melhoria da qualidade de vida (CARMO, 2002).

Uma escola inclusiva deve garantir a todos os alunos o acesso a uma cultura comum, que forneça treinamento básico e educação. Rodrigues (2006) coloca que qualquer grupo de alunos, mesmo que estejam na mesma idade ou na mesma fase, mantém claras diferenças em relação à sua origem social, cultural, econômica, racial, linguística, sexo, religião e são diferentes em suas condições físicas, psicológico, assim como em termos de ritmos de aprendizagem, capacidades, formas de relacionamento, interesses, expectativas e escalas de valores. A escola tem que trabalhar essa diversidade e propor uma intervenção educacional na qual seja possível um excelente desenvolvimento de todos os alunos.

A educação inclusiva é aquela que defende a igualdade de oportunidade para estudantes com diversas habilidades visando alcançar conhecimento. As práticas 
desenvolvidas na disciplina de Educação Física tornam-se uma ferramenta que utiliza suas atividades esportivas para atingir objetivos educacionais, procurando otimizar ou melhorar esses eixos; através de atividades físicas, esportes recreativos e todos os argumentos teóricos que são enquadrados dentro de cada um desses campos (DARIDO, 200I),

O desempenho dos professores de acordo com Nóvoa (2005), na buscada formação, deve ser aquela em que a aquisição de conhecimento oferece condições para o professor ligar a sua prática profissional, despertar as suas competências, uma vez que o conhecimento adquirido durante o curso de graduação em relação ao processo de inclusão nesta área não é suficiente para ter ferramentas adequadas que lhes permitam enfrentar situações adversas. Portanto, é importante que os professores passem por cursos de formação continuada para que forneça conhecimento sobre o processo de inclusão, bem como os passos a seguir para evitar situações de exclusão na sala de aula.

Desta forma, buscamos refletir sobre os processos de inclusão que vem sendo trabalhada no âmbito da Educação Física, procura examinamos a relevância da inclusão no processo educacional desenvolvido pela disciplina em foco. Destaca-se como objetivo geral: averiguar de que maneira o trabalho do professor de Educação Física tem contribuído para o desenvolvimento inclusivo dos alunos que apresentam necessidades educacionais especiais.

\section{BREVE HISTÓRICO PARA COMPREENSÃO DO PROCESSO EVOLUTIVO DA EDUCAÇÃO INCLUSIVA}

O reconhecimento científico do valor educativo e evolução das transformações ocorridas em relação à educação inclusiva nas últimas décadas no nosso país têm levado, nos últimos tempos, a repensar as práticas educativas e o que elas contribuem para a dimensão social do homem. Para se falar em Educação inclusiva é necessário antes de tudo, conhecer o século XXI, que representa a evolução nas instituições educativas, mas o fez sem romper as linhas das diretrizes que lhe foram atribuídas na sua origem: centralista, transmissora, selecionadora, individualista (ALARCÃO, 2003). 
Para educar realmente na vida e para a vida, segundo Alarcão (2003) para essa vida diferente, e para superar desigualdades sociais, a instituição educativa deve superar definitivamente os enfoques tecnológicos, funcionalistas e burocrata, aproximando-se, ao contrário, do seu caráter mais relacional, mais dialógico, mais cultural-contextual e comunitário, em cujo âmbito adquire importância em relação ao que se estabelece entre outras pessoas que trabalham dentro e fora da instituição.

Conforme Rodrigues (2006), depois de uma década da criação do Ano Internacional das Pessoas Deficientes, após a Conferência Mundial de Educação para Todos ocorrida na Tailândia, em 1990, foi criada a Declaração Mundial sobre Educação para Todos. Esta Declaração trouxe como principais objetivos: a satisfação das necessidades básicas de aprendizagem; expansão do enfoque da educação para todos; universalização do acesso à educação - nesse momento o documento ressalta o caso das pessoas com deficiência, esclarecendo que devem ser adotadas "medidas que garantam a igualdade de acesso à educação aos portadores de todo e qualquer tipo de deficiência, como parte integrante do sistema educativo" (RODRIGUES, 2006).

Como relata Rodrigues (2006), a partir da Declaração Mundial de Educação para todos, de 1990, ocorreram o seminário Regional sobre Políticas, Planejamento e Organização da Educação Integrada, para alunos com Necessidades Especiais, na Venezuela, em 1992, e a V Reunião do Comitê Regional Intergovernamental do Projeto Principal de Educação na América Latina, em Caribe, depois realizada no Chile, em 1993, que teve como documento-síntese a Declaração de Santiago.

De acordo com Rodrigues (2006), as recomendações desses encontros deram suporte aos trabalhos para elaboração do Plano de Educação para Todos, no Brasil, proposto em junho de 1993. Cabe lembrar que o objetivo do plano era (ou é) "assegurar, até o ano de 2020, a criança, jovens e adultos conteúdo mínimos de aprendizagem que atendesse as necessidades elementares da vida contemporânea".

Fonseca (2005) também contribui a esclarecer que, em I993, foram elaboradas as Normas Uniformes sobre a Igualdade de Oportunidades para pessoas com incapacidades, aprovadas em Assembleia Geral das Nações Unidas, em que fica 
recomendada a criação, em todas as escolas, de serviços especializados, de modo a integrar as pessoas com deficiências no ensino regular.

$\mathrm{Na}$ declaração de Salamanca, de acordo com Fonseca (2005) que resultou da Conferência Mundial sobre as Necessidades Educativas Especiais, em 1994 na Espanha, onde reafirmou o direito à educação de cada indivíduo, conforme a Declaração Universal dos direitos Humanos foi proposta a adoção de linhas em educação especial. Tal documento trouxe como princípio norteador a ideia de que: todas as escolas deveriam acomodar todas as crianças independentemente das suas condições físicas, intelectuais, sociais, emocionais, linguísticas ou outras. Ainda nesse documento, Fonseca (2005) coloca que assinalaram para incluir:

[...] Crianças deficientes e superdotadas, crianças de rua e que trabalham, crianças pertencentes a minorias linguísticas, étnicas ou culturais e crianças de outros grupos em desvantagem ou marginalizados. E ainda as escolas têm que encontrar a maneiras de educar com êxito todas as crianças, inclusive as que têm deficiências graves (FONSECA, 2005, p. 78).

Dessa recomendação, segundo o autor, é que surge o conceito de Escola

inclusiva. Esse preceito reaviva a declaração universal dos Direitos Humanos, que preconiza educação como um direito de toda a pessoa. Posteriormente ficou assegurado, no nosso país, esse preceito que está presente na Constituição Federal de 1988, também no Estatuto da Criança e do Adolescente (art. 53) de 1990 e na própria LDBEN, aprovada em 1996.

Como afirma Fonseca (2005), através dessas Leis e documentos, nasce a efetivação de uma escola para todos. No entanto, como alerta o autor, quando fala da luta pela escola para incluir todos, encontramos a expressão "uma escola igual para todos", reside aí, um discurso que, apresenta de maneira democrática, mas na realidade pode ter como consequência uma prática discriminatória, visto que as pessoas para qual a escola é oferecida têm diferentes condições biológicas, sociais e culturais.

Alarcão (2003) discorre sobre o princípio da integração nessa mesma década, que foi o eixo norteador da Política Nacional, tornando-se uma meta a ser, efetivada, com mais intensidade do que no início da década de 9o. Isso, em função de uma 
maior exigência dos diretos universais das próprias pessoas consideradas especiais, das organizações não-governamentais e de todas as pessoas envolvidas diretamente com a educação desse alunado especial.

Moreira (2005) contribui a afirmar também, que a partir da década de 70, deu início, timidamente, a formação de professores em cursos das disciplinas de formação pedagógica e, outra parte, como disciplinas específicas, ministradas através de aulas teóricas e práticas. E esse curso, geralmente era o de pedagogia. Mesmo com essas iniciativas, o processo de integração e rejeição, sempre acompanhou esta modalidade de educação, em função até do currículo desenvolvido pelas escolas de ensino médio e superior.

$\mathrm{Na}$ busca pelo entendimento sobre a formação do professor para trabalhar com a Educação Especial, Alarcão (2003) coloca que, nos últimos tempos, sofreu diversas alterações, por exemplo, as discussões relacionadas à formação docente passaram a ter maior amplitude. A tecnicidade, presente no mercado de trabalho naquela época, também passou a ser valorizada no ambiente escolar.

Na década de 90, conforme explica Schön (2000), foram marcados por discussões, encontros, congressos e iniciativas assegurando a educação de pessoas com necessidades especiais. Nesse contexto, a Política Nacional de Educação Especial foi elaborada. Lembrando ainda, que o processo de integração no Brasil não deve ser visto somente para os chamados "deficientes"; as carências, necessidades de trabalho, educação, saúde, habitação, alimentação e outras que não são consideradas "normais": negros, índios, pobres que também lutam por garantias de direitos advogados pela Constituição Federal de 88.

De acordo com Mendes (2006), a expansão da escola a partir da década de 90, provocada pelo aumento do número de vagas, fez aumentar a oferta e a criação de novos cursos de licenciatura. Em decorrência desse fato, professores sem habilitação começaram a ocupar os cargos oferecidos pelas instituições de ensino. Tudo isso contribuiu com a desqualificação e com a desvalorização desse profissional:

[...] Se quisermos contribuir para a mudança dos professores e das escolas, teremos de partir das suas culturas, o que, aliás, será mais coerente com a defesa que se faz, em termos teóricos, de "dar vez e voz" aos professores e 
com a importância atribuída aos contextos parta a compreensão da ação formativa ou educativa (MENDES, 2006, p. 89).

$\mathrm{O}$ autor fala que apesar de progressos evidentes realizados em relação à formação dos professores, a cultura dos docentes é vista da seguinte forma: "a cultura institucional dominante é largamente suportada por uma lógica de prestações individuais e não de desenvolvimento conjunto dos envolvidos no processo do ensino e aprendizagem" (MENDES, 2006, p.90). O que explica a fraca receptividade das ações de formação orientadas para a modalidade de Educação Especial.

Depois de muita luta em torno dessa questão, Mendes (2006) coloca que houve um processo permanente de desenvolvimento profissional, a que todos os educadores têm direito, principalmente quando envolve a formação inicial e continuada, sendo que a diferença essencial entre esses dois processos consiste na formação continuada que ocorre junto ao professor já no exercício de suas atividades.

\subsection{Formação e construção de mudanças na prática da Educação Inclusiva}

Considerando o dispositivo que trata sobre a formação dos professores, as Leis Complementares Estaduais 49/98, 50/98, 206/2004 e a Lei Estadual 7.040/98; que assegura através das Políticas da Secretaria de Estado de Educação, sobre a Valorização dos Profissionais da Educação que ata da formação, acompanhamento e avaliação sistemática da prática educativa dos Profissionais da Educação, de modo a promover avanços contínuos na melhoria da qualidade de ensino; considerando a importância em garantir o quadro permanente dos profissionais efetivos nas unidades escolares estaduais.

As políticas públicas devem dar sustentação para a educação formar um conjunto de ações que abordam, desde o currículo escolar, a formação dos professores e a construção de materiais didático-pedagógicos. A educação especial deveria a cada ano assumir, importância maior, na perspectiva em atender na escola inclusiva o aluno que é sujeito e foco principal de toda a ação pedagógica. O Estado deve buscar dar sustentação para que a educação especial saia do papel e realize o seu atendimento na prática pedagógica, ser imediata no quotidiano da sala de aula, torna-se condição, mister para que tal processo ocorra. 
Mendes (2006) fala das mudanças que com certeza devem ocorrer, pois, os investimentos na ampliação dos recursos humanos, especificamente dos professores de Educação Física principalmente por parte do sistema educacional de ensino, devem incluir ainda, a formação do educador. A formação do professor segundo Botelho (2002), é condição primeira para garantir um processo de escolaridade de qualidade para independentemente do aluno, como também para aqueles que exigem procedimentos, metodologias, processo e formas alternativas e diferenciadas de aprender, do fazer, do escrever, do ler, do ouvir, de comunicação, de interrelação, das atividades lúdicas, dos diferentes modos de acompanhamento no processo escolar.

Nóvoa (2005) e Mendes (2006) advertem que, a maioria das vezes, os professores não encontram um ambiente escolar que ofereça igualdade de oportunidades e condições para o crescimento pessoal e coletivo na compreensão mútua da diversidade, que envolva as questões mais controversas para fazer o processo de inclusão de alunos com deficiência nas escolas comuns, tanto no ensino fundamental como médio. Os autores acrescentam ainda que, existe um distanciamento e até mesmo descrédito com a falta de motivação dos educadores em relação a futuras participações:

[...] Normalmente, os pesquisadores priorizam assuntos de pouca sintonia com o que realmente acontece nas escolas, Tal atitude reforça a ideia de que a prática é de fato por eles entendida como ambiente propício à aplicação de teorias e necessárias ao treino de diferentes métodos científicos, além de ser favorável à ampliação de novos conhecimentos (NÓVOA, 2005, p. 56).

Segundo o autor, ao participar, os indivíduos são imersos durante a maior parte do tempo no mundo teórico - científico. Para o autor, a situação descrita anteriormente possui um forte vínculo com outra forma de distanciamento que também interfere e dificulta o trabalho escolar. Nóvoa (2005) fala da pouca afinidade entre os discursos tratados nos cursos de formação continuada e as reais necessidades dos professores para tratar da diversidade no espaço escolar, isso porque, assim como ocorre com os programas de formação, as investigações realizadas no campo da educação também desconsideram, em sua maioria, os questionamentos $e$ as necessidades dos educadores. 
Para Nóvoa (2005) numerosas ocasiões a inclusão permaneceram no papel, sem que os professores realmente tivessem os recursos e ferramentas para viabilizar um trabalho a contento, que requer uma série de adaptações para as necessidades educacionais específicas que alguns alunos apresentam:

[...] Ainda que desse debate pudessem eventualmente surgir posições diferentes, julgamos que ele não poderia deixar de se traduzir no aprofundamento do sentido de responsabilidade e da busca por novos conhecimentos, sem os quais a formação continuada só operará mudanças menores que, embora não negligenciáveis, não mudarão a escola nem o sistema de ensino (NÓVOA, 2005, p. 6I).

Nóvoa (2005) coloca que toda essa contradição de interesses gera uma crise quando institui um curso para formação dos professores, causada pelas falhas existentes no modelo vigente, que age como se todos os problemas pudessem ser solucionados com a aplicação de técnicas adequadas, ignorando a abrangência dos acontecimentos e a subjetividade dos indivíduos.

Nóvoa (2005) fala ainda, das necessidades da atualidade, que precisam ser complementadas pelas universidades, de modo a desenvolver nos indivíduos a capacidade de mobilizar diferentes saberes que contribuem com a tomada de decisões diante das inúmeras falhas no processo de inclusão. Sendo assim, torna-se ineficaz fundamentar o modelo de formação na transmissão de métodos e técnicas que visem a previsibilidade ou o sucesso a cada problema enfrentado. Ao contrário, precisamos considerar que os indivíduos interpretam de formas diferentes as particularidades do quotidiano e que estas, por sua vez, necessitam de soluções muitas vezes complexas e imediatas como discorre Schön (200o):

[...] E esse comprometimento tem que começar no âmbito escolar. Sem ele, a escola continuará a ficar prisioneira das suas próprias contradições e das relações quase fechadas que muitas vezes mantém com a realidade social e econômica envolvente. E para mudar a situação, não bastarão discursos teóricos e jurídicos bem intencionados, que muitas vezes só contribuem para escamotear a realidade e as divergências entre o que se prega e o que se pratica. Essas divergências são com frequência, flagrantes (SCHÕN, 200o, p. 89).

Neste assunto, Schön (2000) afirma que na formação dos professores deve ser compartilhada a responsabilidade continuamente com os professores, no próprio ambiente em que trabalham. Um trabalho desse tipo segundo o autor, para ser 
realizado e obtenha resultados satisfatórios, necessita de pelo menos quatro fatores: o compromisso dos docentes com as possíveis mudanças; a disponibilidade de tempo e recursos para que o trabalho seja efetivamente desenvolvido; o fim do desperdício da energia do professor com uma gama de atividades burocráticas e o interesse dos dirigentes da própria escola em inovar.

Schön (2000) esclarece que ao inovar é importante conhecer os diferentes pontos de vista dos envolvidos que trabalham nas escolas, sem que haja imposições. Que essa inovação, possa contemplar a estreita relação e o comprometimento que a escola possui com a sociedade na qual está inserida. $\mathrm{Na}$ opinião do autor, essa formação deve trazer embasamentos para proporcionar aos alunos condições para que possam compreender e intervir no mundo do qual fazem parte, pois é uma das funções da escola.

Portanto, para ir mais longe sobre a análise das razões que explicam a eficácia na formação continuada para a Educação inclusiva, no tocante a Educação física, deve ser reconhecido que o cerne da questão está na defasagem entre os discursos teórico e prático da formação e a cultura profissional dos docentes. A formação somente acontecerá, enquanto as pessoas forem capazes de se organizar, mudando o jogo das suas relações. Mas, para isso, é necessário também que as equipes constituídas, articulem a educação dos alunos com deficiência numa escola aberta à comunidade.

Este novo modo de educar, segundo Tardif (2000), vem propor novos questionamentos, talvez impensáveis até o momento, mais criativos e com melhores resultados construir uma escola ou uma sociedade inclusiva, visto que a inclusão somente acontece com a participação do aluno a ser incluído, ser capaz de escolher e de ter autodeterminação na sua educação. E, para que isto aconteça na prática, os educadores devem aprender a ouvir e valorizar o que o aluno tem a contribuir para a sua formação, independente da sua idade ou da sua deficiência.

\subsection{A situação atual da inclusão educacional na educação física}


A situação atual da educação física frente à atenção da educação inclusiva apresenta um quadro crescente, como mostram os dados de algumas investigações que serão detalhadas a seguir. Segundo Darido (200I), por algum tempo, uma resposta urgente à situação atual de atenção à diversidade de alunos foi de extrema necessidade sofrer algumas mudanças na forma de atendimento durante as aulas de Educação Física. Há uma melhoria na inclusão a partir do ensino fundamental porque os professores deram início ao processo de formação nessa área, se sentiram mais preparados e mais conscientes sobre a atenção à diversidade.

Darido (200I) coloca que a Educação Física foi adaptando suas atividades e estrutura curricular no decorrer dos anos, na década de 8o sinaliza mudanças com o parecer CFE n. ${ }^{\circ}$ 215/87 e elaborada a resolução no 03/87 (BRASIL, 1987), passou a dar voz por meio da Educação Física adaptada, o seu objetivo maior consistia na orientação aos educadores dessa área no atendimento dos alunos com deficiência no que envolvia a prática de atividades esportivas. $\mathrm{Na}$ década seguinte estes educadores passam a obter maior autonomia e flexibilidade em relação aos conteúdos curriculares por meio do parecer 215 de 1987 (BRASIL, 1987) que trouxe o seguinte embasamento:

[...] o entendimento de que seria imprescindível a manutenção da linha de autonomia e flexibilidade contida nessa proposta, o que possibilitaria a cada instituição elaborar o seu próprio currículo com ampla liberdade para ajustar-se, numa ótica realista, às peculiaridades regionais, ao seu contexto institucional e às características, interesses e necessidades da sua comunidade escolar, quer no plano docente, quer no discente (BRASIL, 1987, p.3).

Ganha maior flexibilidade curricular, porém ainda aparecerem muitas críticas, pois, a razão pelas quais muitos alunos ficam sem a devida atenção devido à rigidez da organização, dos espaços e dos tempos. Nessa concepção, as diferenças individuais são consideradas como atraso no desenvolvimento, lacunas na aprendizagem, alterações no desenvolvimento da personalidade. Atender mais ao déficit do que à necessidade e mais ao que o aluno tem diferente do que tem o mesmo. Estudos realizados nesse período ainda mostram que tanto no ensino fundamental como médio, uma alta percentagem de professores de Educação Física não atende à diversidade refletida na Lei. 
Daólio (2003) acrescenta que o modelo de currículo que foi instituído trouxe muitas limitações em relação ao processo de ensino-aprendizagem, pois abria um imenso abismo entre a teoria e a prática. Assim, afirma-se que em professores, em geral, não se sentiam preparados o suficiente para atender os alunos com necessidades educativas especiais e os cursos de formação estava longe de abranger essas questões como metodologia de ensino e intervenção

Daólio (2003) coloca que a partir da implantação as Diretrizes Curriculares Nacionais, ficam asseguradas no seu artigo 7.ㅇ a Formação de Professores da Educação Básica no ano de 2002, compreendendo o nível superior, curso de licenciatura, de graduação, trouxe maior autonomia a partir dos cursos de formação para professores levando em consideração as competências.

Conforme Carmo (2002), a partir das Diretrizes Curriculares Nacionais a importância do professor na área da Educação Física foi crescente, pois houve maior desenvolvimento de atitudes positivas sobre a integração escolar. Passam a trabalhar as diferenças que aparecem no âmbito escolar por meio da Educação física adaptada, se dedicam especificamente ao atendimento de alunos com deficiência. Começam a levantar as necessidades de desenvolver atitudes positivas em relação à diversidade, começando com uma formação inicial de professores.

Carmo (2002) fala dos avanços e de novas legislações, resoluções e pareceres, que sustenta o trabalho dos professores dessa disciplina, assim como a aprovação do Plano Nacional de Educação (PNE), com a lei n. ${ }^{\circ}$ I3.005 de junho de 2014 (BRASIL, 2014) com destaque para o artigo $8 . \stackrel{\circ}{\text { : }}$

Art. 8. O Os Estados, o Distrito Federal e os Municípios deverão elaborar os seus correspondentes planos de educação, ou adequar os planos já aprovados em lei, em consonância com as diretrizes, metas e estratégias previstas neste PNE, no prazo de I (um) ano contado da publicação desta Lei. § I. $\mathrm{o}$ Os entes federados estabelecerão nos respectivos planos de educação estratégias que: I - assegurem a articulação das políticas educacionais com as demais políticas sociais, particularmente as culturais; II - considerem as necessidades específicas das populações do campo e das comunidades indígenas e quilombolas, asseguradas a equidade educacional e a diversidade cultural; III - garantam o atendimento das necessidades específicas na educação especial, assegurado o sistema educacional inclusivo em todos os níveis, etapas e modalidades; IV - promovam a articulação inter federativa na implementação das políticas educacionais (BRASIL, 2014, p.I) 
Nesse sentido, o desafio que se apresenta consiste na construção de uma escola que propicie uma mesma qualidade, que se revele na igualdade de oportunidades, sem demagogia, sem paternalismo e com responsabilidade. Portanto, no sentido de incluir os educandos em espaços da diversidade, realizando trocas culturais, respeitando à capacidade de cada aluno para aprender dentro do seu tempo. Dar oportunidades iguais, que nem sempre significa dispensar o mesmo tratamento. A escola deve ter por objetivo possibilitar o mesmo acesso, o que não significa oferecer os mesmos meios.

Para Costa (2004), o ensino da Educação Física como a conversão do conhecimento científico significa, entre outras coisas, trabalhar as atividades através de técnicas e estratégias de modo a facilitar a inclusão. Referem-se ao conjunto de exercícios, procedimentos e meios que permitem um fim a ser alcançado. Deste ponto de vista, atuando por meio das atividades físicas ou habilidades motoras que constitui num conjunto de elementos que tornam o processo de ensino $e$ aprendizagem inclusivo. Quando se trata de inclusão, segundo Rodrigues (2006) percebe uma transformação nos últimos anos nesse setor,

[...] A mudança eficaz depende do empenhamento genuíno dos que a devem implementar e esse empenho só poderá ser conseguido se as pessoas sentirem que controlam o processo. Os professores procurarão melhorar a sua prática, se a consideram como parte integrante da sua responsabilidade profissional, ao mesmo tempo, em que poderão resistir a uma mudança que lhes seja imposta (RODRIGUES, 2006, P. 78).

Para aderir a essas mudanças, colocada pelo autor, estes professores devem ter apoio também do Gestor junto ao processo de inclusão, pois a partir daí será melhorado a prática, deixando de lado a rejeição ao processo de inclusão das pessoas com necessidades educacionais especiais, pois isso implica ainda, o entendimento dos fatores que excluem esta parcela considerável da sociedade.

Chicon (2005) sustenta que a construção coletiva dois saberes que integram o processo do ensino e aprendizagem na área da Educação Física para uma escola que queira trabalhar as diferenças $e$ as potencialidades individuais dos alunos com deficiência, pode ser considerado como fator de crescimento para todos os educandos, tendo em vista que é uma tarefa eu dever ser feita no quotidiano, sendo primordial, 
no entanto, oferecer alternativas que tragam resultados e transformações positivas dentro desse sistema de ensino, pois a tendência é aumentar a cada dia o número de alunos a que venha apresentar necessidades educacionais especiais:

[...] Muitas ações educativas da escola, se tornam meras respostas formais às exigências legislativas, sem qualquer impacto na estruturação das atividades escolares; assim como explica que a maioria dos professores e a maioria das escolas não tenha assumido a autonomia que lhes é concedida por lei (CHICON, 2005, p. 78).

De acordo com Chicon (2005), ao realizar a inclusão dos alunos que apresente necessidades especiais no sistema regular de ensino, o processo a ser instituído é bem mais do que inserir simplesmente o aluno em uma atividade rotineira. Porém, o que se espera do educador, que ao fazer a inclusão do aluno, que vá além de um procedimento normativo, este deve envolve o ingresso, a permanência e vislumbrar o sucesso compreendendo todo o conjunto, visto que o sucesso dos alunos compreende o rendimento escolar desse e a sua interação social com a comunidade escolar:

[...] Nesse ponto, a inclusão pelo professor de Educação física, nas suas atividades, deve, primeiramente, "integrar" o aluno com atividades adaptadas. "Pela integração, o aluno tem acesso às escolas através de um leque de possibilidades educacionais, que vai da inserção às salas de aula do ensino ao desenvolvimento integral deste à comunidade em que está inserido" (MANTOAN, 2009, p. 68).

Nesse entendimento, o autor fala de inclusão não apenas na forma da lei ou do papel, tudo isso implica o retorno do aluno com necessidades especiais, apto para conviver na sociedade. Trabalhar mais atividades que promovam colaboração mútua, jogos cooperativos e atividades menos competitivas. Com essas medidas, o educador deve buscar um tempo maior de comprometimento motor, um clima nas atividades desenvolvidas, uma organização e controle adequados, para facilitar a inserção, por conseguinte, deve combinar as diferentes maneiras de agrupar alunos.

Para Rodrigues (2006) também, ao exercer essa prática, a escola deve buscar meios para o professor crescer com o aluno, proporcionando condições que favoreça a construção do aprendizado, através de uma formação específica, que seja apropriada e eficaz para que estes alunos possam enfrentar as disparidades existentes no processo de educar, e consigam vencer os grandes desafios de uma sociedade em constantes e 
profundas transformações. Com atividades integradas que podem ser realizadas com alunos com deficiência ou sem eles. Nesse sentido, o autor destaca ser importante a metodologia utilizada, trabalhar com o que é positivo para o educando, verificar se este está interessado.

Portanto, no que diz respeito ao processo de inclusão, por parte deste profissional, existe a necessidade de superar desafios, pois é valido lembrar que para obter um resultado satisfatório visando a inclusão do aluno, o professor precisa adquirir conhecimento ou estratégias específicas, tudo isso supõe a combinação que comporta conhecimentos específicos. Nesse aspecto, o professor de Educação Física pode oferecer um aprendizado de qualidade, proporcionar condições para que os seus alunos possam ir além, viabilizando e ampliando possibilidades para o atendimento das diferentes necessidades educativas existentes, oportunizando, desta forma, diferentes alternativas que subsidiem o processo do ensino e aprendizagem, da construção e readaptação destes recursos. Nesse sentido, torna-se necessário que estes educadores revejam as suas práticas sempre, as estratégias que estão a utilizar para que possam auxiliar na efetiva melhoria de ensino e procurar ampliar as oportunidades inclusivas aos educandos.

\section{CONSIDERAÇÕES FINAIS}

Ao longo este estudo foi possível desenvolver um extenso trabalho de levantamento e compreensão por meio da revisão da literatura, aprofundando nos aspectos mais relevantes que envolvem a educação inclusiva nas aulas de Educação Física. O objetivo norteador do estudo consistiu em averiguar de que maneira o trabalho do professor de Educação Física tem contribuído para o desenvolvimento inclusivo dos alunos que apresentam necessidades educacionais especiais.

Inicialmente, compreendeu-se que existe um crescente reconhecimento da Educação Inclusiva no Sistema Regular de Ensino, como forma prioritária para atender os alunos com necessidades educativas especiais e que esta disciplina, na prática, apresenta muitas mudanças advindas dos esforços dos professores que tem 
empenhado para inserir atividades adaptadas para atender com qualidade os alunos com deficiência.

Outro fator considerado importante neste estudo, em relação à formação continuada, é a responsabilidade da forma que continuamente os professores devem buscar pelo conhecimento, no próprio ambiente em que trabalham. Esse tipo de trabalho encaminha para obtenção dos resultados satisfatórios, necessita de, pelo menos, quatro fatores: o compromisso dos docentes com as possíveis mudanças; a disponibilidade de tempo e recursos para que o trabalho seja efetivamente desenvolvido; o fim do desperdício da energia do professor com uma gama de atividades burocráticas e o interesse dos dirigentes da própria escola em inovar. Os professores, ao fazerem a inclusão, procuram fazer um trabalho personalizado, adaptado a todas as crianças conforme as suas faixas etárias.

Portanto, o estudo trouxe o entendimento de que as atividades educativas do aluno com deficiência devem ser dirigidas a todas as dimensões da pessoa, não à sua limitação ou deficiência. A intervenção não se refere apenas à esfera cognitiva, mas inclui aspectos como o emocional, sócio relacional e motor, que interagem contínua e inevitavelmente com a mesma função intelectual. Dessa maneira, percebe que há uma atitude positiva em relação trabalho de inclusão por parte do professor de Educação física, mas reconhece as limitações pedagógicas para poder atender à diversidade, o que supõe um déficit educacional em professores. Conclui-se que a atividade física tem um efeito positivo sobre o processo inclusivo e a construção na formação do educando.

\section{REFERÊNCIAS BIBLIOGRÁFICAS}

ALARCÃO, I. Formar-se para formar. Revista Aprender, Aveiro, n. 15, pp. 19 - 25, 1993.

BOTELHO, P. Linguagem e letramento na educação de surdos: ideologias e práticas pedagógicas. Belo Horizonte: Autêntica, 2002.

BRASIL. 2005. Disponível em: http://www.planalto.gov.br/ccivil_03/_ato20042006/2005/decreto/D5626.htm. Acesso em: 14/05/2012

BRASIL. Constituição Da República Federativa Do Brasil. Brasília, DF: Senado Federal, I988. 
CARMO, A. A. Educação Física: crítica de uma formação acrítica: um estudo das capacidades e habilidades intelectuais solicitadas na formação do profissional de Educação Física. Universidade Federal de São Carlos, 2002.

CARVALHO, RositaEdler. Temas em educação especial. 2. ed. Rio de Janeiro: WVA, 2000.

CHICON, José Francisco. Inclusão na Educação Física escolar: construindo caminhos. $432 \mathrm{f}$. 2005. Tese (Doutorado em Educação) - Programa de PósGraduação em Educação, Faculdade de Educação, Universidade de São Paulo (FEUSP), São Paulo, 2005.

COSTA,V. L. Prática da Educação Física no Io grau: modelo de reprodução ou perspectiva de transformação? São Paulo: Ibrasa, 2004.

DAÓLIO, J. A representação do trabalho do professor de Educação Física na escola: do corpo matéria-prima ao corpo cidadão. Revista Brasileira de Ciências do Esporte, Campinas, p.I8I- I86, 2003.

DARIDO, S. C. Teoria, prática e reflexão na formação profissional em Educação Física. Motriz, Rio Claro, v. I, n. 2, 1995. 9MARQUES, U. M.; CASTRO, J. A. M.;

FONSECA, V. Educação Especial. Porto Alegre: Artes Médicas. 2005.

MANTOAN, Maria Teresa Eglér. Produção de conhecimentos para a abertura das escolas às diferenças: a contribuição do Leped. Rosa, Dalva E. Gonçalves \& Souza, Vanilton C. Políticas organizativas e curriculares, educação inclusiva e formação de professores. Rio de Janeiro: DP\&A, 2009.

MEDINA, J. P. S. A Educação física cuida do corpo e "mente". São Paulo: Papirus, 1983.

MENDES, E.G. A radicalização do debate sobre inclusão escolar no Brasil. Revista Brasileira de Educação. São Carlos, vol. II. n. 33. p. 387- 405, set./dez. 2006.

NÓVOA, A. Concepções e práticas de formação contínua de professores. In Formação Contínua de Professores: Realidades e Perspectivas. Ed. São Paulo: Cortez, 2005.

SCHÖN, Donald A. Educando o profissional reflexivo: um novo design para ensino e a aprendizagem. Trad. Roberto Cataldo Costa. Porto Alegre: Artes Médicas Sul, 2000.

TARDIF, M. Saberes profissionais dos professores e conhecimentos universitários: elementos para uma epistemologia da prática profissional dos professores e suas consequências em relação à formação para o magistério. Rio de Janeiro: ANPED. 2000. 